\title{
Os Significados das Emoções na Educação das Crianças
}

\author{
SILVA, Eulina de Almeida da [1]
}

SILVA, Eulina de Almeida da. Os Significados das Emoções na Educação das Crianças. Revista Científica Multidisciplinar Núcleo do Conhecimento. Edição 09. Ano 02, Vol. 02. pp 88-110, Dezembro de 2017. ISSN:2448-0959. Link de Acesso: https://www.nucleodoconhecimento.com.br/educacao/emocoes-na-educacao

\section{RESUMO}

As emoções podem ser entendidas como distintas reações químicas e neurais, em padrões que desempenham circunstâncias no organismo, unidas ao corpo, ajudando a preservar a vida. Possibilidade um melhor entendimento dos aspectos que envolva as emoções na educação das crianças. Este estudo tem como objetivo geral analisar quais os aspectos emocionais que influenciam na aprendizagem das crianças na escola. Como objetivos específicos a) busca-se como se formam às emoções das crianças; b) Conhecer sobre as emoções dela a partir de uma análise teórica; c) Perceber a importância emocional na educação infantil; d) Compreender as estratégias utilizada para o desenvolvimento das emoções pelos profissionais da educação. Essa pesquisa justificou-se pela necessidade de conhecer e compreender as questões referentes ao desenvolvimento integral das crianças levando-se em consideração o emocional do indivíduo. Metodologicamente, o universo pesquisado envolveu um estudo com pesquisa qualitativa através do levantamento bibliográfico de questões acerca dos conceitos emocionais que envolvem o aprendizado dos alunos na educação infantil. Para a interpretação, a análise dos dados obtidos e conclusão da pesquisa, serviram de embasamento teórico, os estudos sobre o que é emoção e como ela contribui para o desenvolvimento humano de forma equilibrada. Para isto buscou-se como referencial teórico: Damásio (2000, 2004); Bordignon (2008); Goleman (2007); (Bock 1999); Rosseti-Ferreira (2003); Wallon (1999); Negrine (2002), contribuindo sobre o que é emoção e como ela é importante para o desenvolvimento humano de forma equilibrada. Os principais resultados indicam que os aspectos emocionais do ser humano contribuem de forma especial com a formação do caráter, da moral e da consciência, considerando-se, no entanto, que a emoção está ligada a todos os órgãos do corpo.

Palavras-chave: Emoção, Aprendizagem, Criança.

\section{INTRODUÇÃO}


Argumentando sobre emoções Damásio (2000) fala que são distintas reações químicas e neurais, em padrões que desempenham circunstâncias no organismo, unidas ao corpo, ajudando a preservar a vida. Portanto este artigo tem o propósito de analisar quais os aspectos emocionais que influenciam nas aprendizagens das crianças na escola, principalmente na fase em que ela adquire habilidades para seu desenvolvimento tanto afetivas como educativa. Por isso torna-se importante entender como se desenvolve as emoções na educação das crianças. Bordignon (2008, p. 125) fala que "[...] a educação deve ser entendida como relação dialógica entre sujeitos que se educam, num duplo sentido de relação".

Baseando-se no sentido de apropriação de mundo real através das significações que lhe causam, sendo expressão dos sentimentos e emoções, determinantes de acordo a vários fatores que por ela pode ser vivido através do lúdico. Assim estudar o processo da emoção possibilita assimilar as mais variadas formas de convivência cultural e social em que a criança está inserida as quais lhes dão suporte para o processo de sua educação. De certo que é pela educação que surge nas crianças uma aceitação das normas sociais as quais lhes proporcionam aquisição de autonomia através da experiência educativa tornando-se em aprendizagem significativa. Relação com o termo abordado por Erikson (1987 apud Bordignon, 2008). A virtude que surge é o propósito, à vontade, o desejo de ser, de fazer e conviver, sintetizada na expressão: "Eu sou o que posso imaginar que serei". Deste modo, pode-se dizer que o ser humano constrói sua identidade pessoal paralelo a construção de seus ideais legitimados pela emoção.

Nesta fase de construção do emocional, tão importante como qualquer outra habilidade adquirida pela educação, quanto aos estímulos emocionais, deve haver um maior foco a aprender conhecer os limites do nível psíquico que se estabelece neste percurso educacional, observados em momento de estágios do desenvolvimento de cada emoção. Aprender a controlaras reações emocionais, entendendo-se primeiro a si próprio sem se esquecer deste lado sensível que se não controlado ou bem direcionado geram consequências para toda uma vida. Assim, a construção do conhecimento ocorre numa troca de experiências entre seus pares, professor, aluno, escola e comunidade em geral.

Quanto na argumentação Freud (1973 apud Barros, 2005) [...] "nossos desenvolvimentos pessoais e emocionais são determinados durante os primeiros sete anos de vida". Daí que vem a significação da frase escrita por Freud (1973, p. 85) "a criança é o pai do homem”, pois, é a parti das significações e experiências adquiridas pela criança que se formaliza o adulto.

Corroborando com o exposto, Erikson (1987) faz contribuições significativas sobre o desenvolvimento psicológico saudável na infância, são questões que ajudam durante a fase adulta em seus aspectos que envolva o todo para sua aprendizagem.

Sendo assim, acredita-se que a educação significativa e bem direcionada dentro do âmbito das relações em que a criança está inserida lhe proporciona formação emocional como um elemento motivador na aprendizagem de cada criança, a motivação está em ajudar a criança a buscar e interagir de forma participativa.

Desse modo questiona-se: como os aspectos emocionais influenciam na aprendizagem das crianças na escola?

Este estudo tem como objetivo geral analisar quais os aspectos emocionais que influenciam na 
aprendizagem das crianças na escola.

Como objetivos específicos busca-se:

a) Buscar como se formam as emoções das crianças.

b) Conhecer sobre as emoções delas a partir de uma análise teórica.

c) Perceber a importância emocional na Educação Infantil.

d) Compreender as estratégias utilizadas para o desenvolvimento das emoções pelos profissionais da Educação.

Este estudo foi desenvolvido através de um referencial teórico tratando do significado das emoções das crianças na educação.

A escolha desse tema se deu pela necessidade de entendimento do significado das emoções na educação das crianças, pois é importante ver a criança como um ser único, com suas individualidades próprias. Sendo através do ato de brincar que ela vivencia e interage com o mundo a sua volta.

Torna-se importante entender todo o contexto que envolve as emoções na formação das crianças porque, na perspectiva da educação infantil, é possível que nos deparemos com desafios no processo de construção significativas na educação das crianças, sendo assim, este estudo possibilita uma melhor compreensão dos limites e possibilidades da formação das emoções das crianças na educação infantil.

Contribuindo com o esclarecimento do papel significativo que tem a formação emocional, a função das pessoas que estão responsáveis pela educação na sua prática cotidiana, quais as estratégias que estes responsáveis utilizam, se existem desafios de lidar, se há estratégias para ajudar as crianças na superação dos conflitos emocionais, como ocorre a formação emocional frente aos desafios educacional.

\section{As Emoções}

A criança chora, ri, tem medo, raiva, alegria, tristeza, e sente amor. Tudo isso são emoções. Elas fazem parte da vida das pessoas desde sua infância contribuindo para seu desenvolvimento psíquico unido a formação motora sendo intrínsecas à dimensão física das pessoas. Isto é, uma reação do organismo ao seu bem-estar ou mal-estar fisicamente. Nas palavras de Damásio (2000, p. 74), podemos considerar que:

Emoções são conjuntos complexos de reações químicas e neurais, formando um padrão; todas as emoções têm algum tipo de papel regulador a desempenhar, levando, de um modo ou de outro, à criação de circunstâncias vantajosas para o organismo em que o fenômeno se manifesta; as emoções estão ligadas à vida de um organismo, ao seu corpo, para ser exato, e seu papel é auxiliar o organismo a conservar a vida.

As sensações que o corpo humano sente são reflexos das estruturas neurais. O corpo humano possui sensores que dão respostas aos estímulos da mente numa espécie de movimento sincronizado. É um movimento harmonioso em que todos os órgãos são vitais neste processo.

Todas as pessoas têm emoções e estão em constante modificação, no sentido amplo da relação entre objetos e repostas emocionais. Nas palavras de Damásio (2004, p. 62) [...] "as emoções são um meio natural de avaliar o ambiente que nos rodeia e reagir de forma adaptativa”. Apresenta-se então, uma 
hipótese de emoção:

1. Uma emoção propriamente dita é uma coleção de respostas químicas e neurais que formam um padrão distinto.

2. As respostas são produzidas quando o cérebro normal detecta um estímulo-emocional-competente (EEC), o objeto ou acontecimento cuja presença real ou relembrada desencadeia a emoção. As respostas são automáticas.

3. O cérebro está preparado pela evolução para responder a certos EEC com repertórios de ação específicos. Mas a lista dos EEC não se limita àqueles que foram prescritos pela evolução. Inclui muitos outros adquiridos pela experiência individual.

4. O resultado imediato destas respostas é uma alteração temporária do estado do corpo e do estado das estruturas cerebrais que mapeiam o corpo e sustentam o pensamento.

5. O resultado final das respostas é a colocação do organismo, direta ou indiretamente, em circunstância que levam à sobrevivência e ao bem-estar (DAMASIO, 2004, p. 61).

As emoções são expressões por ações ou movimentos, processos públicos que ocorre no rosto, na voz ou por certos tipos de comportamentos precedidos quando o cérebro detecta um estímulo - emocionalcompetente. Embora certos comportamentos de emoção não sejam percebidos, mas ocorrem no teatro do corpo, as respostas que se tem são o posicionamento do organismo. Com relação à aprendizagem já nascemos com dispositivos de regulação automáticas da vida, com reações prontas desde, onde a aprendizagem desempenha um papel importante determinando de que maneira e momento será usado. Contudo a regulação da vida conduz com a finalidade de produzir um estado de vida melhor, produz aquilo que nós, seres pensantes, identificamos como bem-estar. Damásio (2004, p. 37) fala que as manifestações emocionais precedem os sentimentos "as emoções foram construídas a partir de reações simples que promovem a sobrevivência de um organismo e que foram facilmente adotadas pela evolução".

Conforme o homem passa a compreender, controlar e educar as emoções se torna uma habilidade para a vida. E é através da conjunção características humanas, ideias, valores, princípios e juízos os tornam especial, no sentido de ser humano único, com características especiais.

Todos os seres têm a capacidade de identificar as emoções consideradas básicas, ou universais, entre toda espécie humana, reconhecendo as características das emoções nos outros através das expressões faciais, que seriam as: alegria, tristeza, medo, raiva, surpresa ou repugnância. Bordignon (2016, p. 9) afirma que “as formas de pensar e agir estão ancoradas nas emoções básicas da pessoa, não se pode negá-las, nem reprimi-las. Elas integram antropologicamente a dinâmica afetiva da pessoa por toda sua vida”. Tem também as emoções secundárias ou sociais, como embaraço, ciúme, culpa ou orgulho. E emoções de fundo, como bem-estar ou mal-estar, calma ou tensão. De certo que toda experiência significativa causa impacto sobre a mente humana, mas estes impactos dos sentimentos a partir do momento que a emoção é desencadeada induzem os sentimentos. Mas sentir requer que o organismo tenha consciência.

Definição simples de emoção como uma mudança transitória no estado do organismo, é a representação dessa mudança transitória no estado do organismo, por meio de padrões neurais e das imagens resultantes (DAMÁSIO, 2004, p. 63).

A partir do momento que conhecemos que estamos tendo um sentimento não nesse exato momento que 
começou as reações dentro do organismo, o sentimento não começou no exato momento em que foi conhecido, mas bem antes de revelar a consciência.

Damásio (2000, p. 57) faz a separação dos estágios:

Um estado de emoção - que pode ser desencadeado e executado inconscientemente; um estado de sentimento, que pode ser representado inconscientemente, e um estado de sentimento tornado consciente, isto é, que é conhecido pelo organismo que está tendo emoção e sentimento.

É importante que a consciência esteja presente porque os sentimentos influenciam o indivíduo que os tem. A evolução das emoções se estabelece antes que surgem a consciência e apareça com distinção para cada pessoa. "Assim como a emoção, a consciência relaciona-se à sobrevivência do indivíduo e que, tal como a emoção a consciência estar alicerçada na representação do corpo" (DAMÁSIO, 2000, p. 58). Ele também argumenta que a emoção e a consciência embora sejam manifestações diferentes suas estruturas podem estar ligadas.

De toda a organização do componente biológico, são inicialmente conduzidas para a consciência inicial antes das induções dispostas ao meio. Como forma de compor possibilidades deste organismo representar no inconsciente sua identidade como pessoa. Apesar da ciência estar voltada ao fato da atenção, sob a visão de um objeto. Damásio argumenta que a atenção básica precede a consciência, ao passo que a atenção focalizada acompanha o desenvolvimento da consciência.

O conhecimento de um determinado objeto se dá pelo fato de uma relação entre o organismo e o objeto. Constrói conteúdo da consciência a partir do momento que o organismo se empenha na interação junto com o objeto causando mudanças neste organismo. Entende-se assim a formação biológica da consciência, considerando que todos esses processos constituem em padrões necessários nessa relação do entendimento das emoções.

Goleman (2007, p. 303) entende que "emoção se refere a um sentimento e seus pensamentos distintos, estado psicológico e biológico, gerando uma gama de tendência para agir".

Durante esses processos em que atuam os distintos estados mentais há a transição de acordo como cada atuação, vivida pela a criança com pertencimento comum já estabelecido desde seu nascimento ou como ser humano é vista como herdada. Então estes contatos com os mais variados acontecimentos sociais mudam para um ato padrão de complexidade humana que buscar conscientemente se auto determinar. Não que este processo seja de um dia para o outro, mas um trabalho diário de forma racional tentando uma transformação, educando as emoções diariamente de modo a contribuir com o aprendizado das crianças.

As emoções são estruturadas de maneira que os sentimentos pelo encanto horror, satisfação, desamor assim também como harmonia desencadeando as emoções expressas pelas respostas do próprio corpo. Para Bock (1999):

Não temos por que esconder nossas emoções. Elas são nossa própria vida, uma espécie de linguagem na qual expressamos percepções internas; são sensações que ocorrem em resposta a fatores geralmente externos. São fortes, passageiras; intensas, mas não imutáveis. Isto quer dizer que o que hoje nos 
emociona, poderá amanhã não nos emocionar mais (BOCK, 1999, p. 196).

$\mathrm{Na}$ zona de desenvolvimento em que permitissem identificar interações e percepções como mediadoras dos processos psicológicos de forma de intercalar e interagir o ensino com razão e emoção. Os processos psíquicos utilizam uma teoria ao analisar a razão de maneira que inter-relacione a emoção.

Segundo Bordignon (2008, p. 65-66):

Uma forma concreta para a formação afetiva da criança é seguir os cinco passos propostos por Goleman (1996):

$1^{\circ}$ Perceber as emoções da criança, antes, porém, identificar, aceitar e elaborar a sua própria experiência afetiva, para poder trabalhar, empaticamente, a experiência afetiva dos filhos. Acolher a dialética da autonomia e da vergonha e da dúvida.

$2^{\circ}$ Reconhecendo a emoção como uma oportunidade de intimidade e orientação: As emoções e os sentimentos são profundamente pessoais, íntimos e misteriosos, e em sua maioria, difíceis de perceber e expressar. Nem sempre é possível reconhecer e expressá-los no momento em que ocorrem. Importa acolher esta dificuldade e oportunizar momentos de expressão dos sentimentos.

$3^{\circ}$ Ouvir com empatia e legitimar os sentimentos da criança, colocando-se no lugar da criança, buscando perceber como ela sente, pensa e age, buscando captar, a sua verdade, em sua realidade. Prestar atenção, olhar para a criança, ouvir incondicionalmente, aproximar-se, tocar, suspendendo julgamentos. Reservar tempo para ouvir de forma sistemática e organizada a criança.

$4^{\mathrm{o}}$ Nomear e verbalizar as emoções e os sentimentos, isto ajuda a criança a descrever a sua experiência afetiva. Pode-se colaborar na descrição do que ela está sentindo, criando imagens, gestos, descrevendo...

$5^{\circ}$ Impondo limites e ajudando a criança a encontrar soluções e alternativas. A partir da criança, analisar as causas e as consequências da realidade afetiva, em termos de valores pessoais, familiares e transcendentes. Elaborar estratégias e um sistema de vigilância ao nível da criança, fazendo-a partícipe de todo o processo. Fazer a criança colocar-se no lugar dos outros ajuda no processo de crescimento. (BORDIGNOM, 2008, p. 65-66).

Estes são pontos importantes para a formação dos valores e aprendizagem que abrange em sua formação física, através das experiências afetivas que lhes proporcionam oportunidade para seu desenvolvimento emocional e aprendizagem para a vida. Ainda segundo Bordignon (2008 apud Imoda, 1996) argumentando sobre o desenvolvimento da educação e emoções:

Falando da educação e as emoções, Imoda (1996, p. 263) diz que a "ortopatia" é importante para a $\operatorname{ortodoxia}^{[3]}$ e a ortopráxis"[4], isto é, à formação para o conhecimento e para a ação deve preceder a formação das emoções, dos sentimentos. De outra forma dizemos que a formação para a verdade e para a ação deve estar fundamentada na formação para o amor (BORDIGNON,2008. p. 24).

A finalidade da educação centrada na formação para o amor está em preparar o indivíduo para pensar e agir buscando caminhos e administrar as emoções. Com objetivo de desenvolver a formação afetiva para 
conhecer o mundo de forma que ele possa desenvolver suas capacidades e habilidades ao longo de sua vida.

Maturana (1999, p.320), faz a seguinte afirmação:

[...], não há desenvolvimento corporal, psíquico e social sadio na negligência do amor; não há nenhuma saúde corporal, psíquica e social adulta no meio de conversações recorrentes que negam a auto-aceitação; e não há nenhuma relação corporalmente, psiquicamente e socialmente sadia no meio de conversações recorrentes que negam o amor. Isto é assim porque nós, como seres humanos, pertencemos à história biológica centrada na conservação do amor.

Argumentando ainda sobre as emoções, no que tange a conservar a vida quando questionamos sobre a evolução humana, o mais primitivo modo que constitui a formação do cérebro em torno do início da medula espinhal este controla as funções que cada órgão do corpo humano desempenha, formação que atuam de modo sincronizado para o conjunto programado no andamento de cada órgão do corpo. Estas promovem momentos de reflexão sobre a sobrevivência considerada ao longo da história evolutiva humana, a emoção, a mais refinada das capacidades humanas.

Sendo assim as emoções integram no todo da pessoa para aquisição em termos de habilidades e reconhecimento das capacidades que se manifestam durante toda a vida.

As expressões das emoções básicas são essencialmente representadas como:

\section{Tabela 1}

\section{EMOÇÕES E SENTIMENTOS}

- Aceitação, amizade, solidariedade, felicidade,

AMOR

bondade, misericórdia, confiança, segurança,

Felicidade, disposição, bem-estar, sorriso no rosto,

ALEGRIA

autoestima e autoimagem positivas...

- Fechamento, sofrimento, solidão, inimizade,

TRISTEZA

egoísmo, infelicidade, mágoa, melancolia, ...

- Timidez, ansiedade, preocupação, angústia,

MEDO

temor, fobia, apreensão, pânico, depressão, ...

- Ira, revolta, ressentimento, hostilidade,

RAIVA

agressividade, ódio, violência, irritação, indignação, ...

FONTE: Bordignon, 2016, p. 10

\subsection{Educação Emocional}


"Ensinar é um gesto de generosidade, ensinar é um gesto de amor" (TIBA, 1998, p. 61). Desde os primeiros contatos da criança com o mundo acontece evoluções fazendo com que as emoções sejam expressas a medida da relação do objeto externo, estímulos moldados conforme o desenvolvimento vivido pelo meio.

Vygotsky (1989) afirma que a condição de compreensão e comunicação são compartilhadas desde o nascimento. Só diferencia as formas de operação.

Como forma de compor possibilidades deste organismo representar no inconsciente sua identidade como pessoa. Apesar de a ciência induzir ao fato da consciência está voltado ao fato da atenção sob a visão de um objeto. Damásio (2000) argumenta que a atenção básica precede a consciência, ao passo que a atenção focalizada acompanha o desenvolvimento da consciência.

Na concepção de Goleman (2007), nós sentimos influencia na maneira como nós pensamos, sendo que a capacidade consciente das atribuições que define a forma de reagir de cada pessoa a medida das coisas que pensamos, pois são elementos importantes na vida que não é só a razão desafiadora, mas as emoções. Saber sentir de modo subjetivo baseado na capacidade de produção de resultados, ou seja, saber agir reavaliando as atitudes, pensamentos e resultados, todos bem sincronizados. Goleman (2007, p. 152) faz sua contribuição dizendo que a aprendizagem emocional promove aptidões: as meninas são "capazes de captar sinais emocionais verbais e não-verbais, de expressar e comunicar seus sentimentos", quanto aos meninos eles tem a habilidade em "minimizar emoções que digam respeito a vulnerabilidade, culpa medo e dor". Estas são implicações que geram reações de bom comportamento, saber frear os impulsos, aguardar a vez, seguir as orientações pedir ajuda do professor e expressar-se. Bordignon (2008, p. 72) fala que deve aproveitar esses momentos para que a criança desenvolva mais conhecimento através do brincar, pois, é pela "expressão que a criança explora e vivencia" os sentimentos adquiridos assim como os que vão sendo construídos.

Colaborando com o disposto Watson (1946, p141) "demonstrou que muitas de nossas reações emocionais foram adquiridas através de nossas experiências durante a infância”. Já Bruner (1979 apud Barros, 2005) argumenta que as crianças têm uma curiosidade natural dentro de si para estímulos a aprendizagem

A aprendizagem requer a significações das informações para que se torne conhecimento. Assim sempre que se aprende algo novo há um universo de significações que passam pela área cognitiva, afetiva, motora e social. Sendo essas questões, uma característica essencial do ser humano que é através de fatores correspondente ao emocional, atividades diárias que a criança vai construindo o conhecimento das coisas e do mundo.

Admirável capacidade humana essa de aprender com os outros da mesma espécie e de se adaptar aos mais variados ambientes e situações. Estranho pensar que ela se funde em nossa extrema imaturidade motora ao nascer, que nos faz depender dos outros por longos anos. Em contraposição, nossa rica expressividade ao nascer, favorece nossa comunicação com os outros. Aqueles que nos cuidam medeiam nossas relações com o mundo (ROSSETTI-FERREIRA, 2003, p. 10).

As crianças desenvolvem-se por meio das atividades representativas pela qual é inserida, a imitação, pois é através dela que a criança aprende. Da capacidade que a criança tem de imitar, sinaliza-se o bom curso 
do desenvolvimento mental e motriz de uma criança. Todas as emoções usam o corpo como teatro (meio interno, sistemas visceral, vestibular e músculo - esquelético, mas as emoções também afetam o modo de operação de inúmeros circuitos cerebrais: a variedade de reações emocionais é responsável por mudanças profundas na paisagem do corpo e do cérebro (DAMÁSIO, 2000, p. 364). "As emoções só são desencadeadas após um processo mental de avaliação que é voluntário e não automático" Damásio (2000, p. 147). No entanto, é por meio do corpo que o homem organiza seu estar e ser no mundo onde se distingue os seguintes níveis:

1. o nível do espaço-tempo físico-biológico pelo corpo próprio. É neste nível onde se forma e consolida a imagem (representação), a postura (espaço) e o ritmo (tempo) do corpo; bem como intervém profundamente a sexualidade, transposta da esfera biológica para a humana.

2. o nível do espaço-tempo psíquico do estar no mundo, por meio da afetividade em termos de emoção e sentimentos. A sexualidade passa do espaço-tempo biológico para o espaço-tempo psíquico, modelando o ser no mundo pela afetividade.

3. o nível do espaço-tempo social pela linguagem e comunicação como domínio da expressividade do corpo próprio em símbolos e comportamentos sociais.

4. O nível do espaço-tempo cultural, desde as práticas culturais de arte, jogos, ritos, hábitos, comportamentos, refeições... e os adestramentos e modelagem da figura corporal em academias, artes...

(BORDIGNON, 2016, p.12)

Ter o conhecimento do significado das emoções na aprendizagem da criança é ter a compreensão de todo o conjunto em que se denomina a partir do estímulo do meio, sem negar a origem biológica dessas competências.

Considerando as emoções de fundo, nada mais é do que um ato representativo sem que precise ser dita uma palavra, para perceber as reações "tensa" ou "irritadiça", "desanimada" ou "entusiasmada", "abatida" ou" animada", são identificados como emoções de fundo, sendo esses observados através de detalhes do comportamento, postura do corpo, velocidade, mudanças mínimas dos olhos e o grau de redução de movimentos dos músculos da face, (DAMÁSIO, 2000).

Para uma nova realidade da educação infantil será necessária a atuação de profissionais de diversas formações, os quais irão ampliar e solidificar os alicerces necessários ao desenvolvimento de processos que favoreçam a construção do indivíduo como pessoa.

Portanto o educador que busca proporcionar em sua pratica o verdadeiro sentido do ensino preocupado com a qualidade, dando significados as emoções na educação das crianças, pois neste ambiente se formaliza as relações que a criança desenvolve através da educação. Sendo assim afeto, amor é indispensável.

Na visão do teórico Wallon (1995 apud ARANTES, 2003) entende que a pessoa se constitui por processos psíquicos. Ações que constituem todo o desenvolvimento humano analisando pelo ato motor, afetivo e inteligência conforme a interação que o sujeito constrói com o meio social. Desde os primórdios as emoções estão presentes, predominando a complexidade do desenvolvimento nos primeiros anos de vida da criança, período em que compreende as funções psíquicas, mais difíceis a serem desenvolvidas na 
idade adulta.

A criança descobre-se pessoa através da percepção do próprio corpo, sensório-motor, percepção que interfere, ao longo da vida no conceito de autoestima e autoimagem, a celebração, forma de ser e relacionar-se. Esta descoberta, como reconhecimento de si é essencial para relacionar-se consigo e com os outros. O corpo é a manifestação da pessoa diante de si e dos outros como sujeito autônomo e livre. (BORDIGNON,2016, p. 5)

Através da percepção do corpo é que a criança se descobre processo que interfere no decorrer da vida.

\subsection{Desenvolvimento da Criança}

Entender como acontece o desenvolvimento da criança é uma referência aos processos de desenvolvimento humano, estudado por teóricos, buscando entender suas origens. Para Negrine (2002, p.24), o processo de desenvolvimento humano, partiu de diferentes modos, embora ligados e influenciados. No sentido amplo da ideia, desenvolvimento humano sucede de dois sistemas: de um lado o método de maturação, em que a origem é biológica; por outro, o processo de aprendizagem, o qual tem origem histórico-cultural.

Para as crianças, é muito importante que a pessoa responsável por sua educação tenha amplo conhecimento das teorias que tratam do desenvolvimento humano, visto que são fundamentais para que a formação seja significativa. No entanto e reflete dos princípios teóricos a partir das teorias piagetiana e vygotskiana. Para o entendimento da evolução dos processos (maturação e aprendizagem).

Partindo da argumentação que as aprendizagens produzidas pelo estímulo do meio, Vygotsky defende que o processo de aprender é decorrente de fatores histórico-culturais, sendo estes que aceleram o processo de maturação. Os costumes gerados desses fatores temos os hábitos, as ações e as formas de relação dos adultos que são influenciados pelo desenvolvimento psíquico e no comportamento da criança (NEGRINE,2002, p.27).

Contudo o contexto educacional pode dispor dos símbolos (o mundo dos sinais ou o faz de conta) na atividade infantil como mediadores do desenvolvimento mental, pois a imitação dos atos dos adultos que a criança fará através das brincadeiras o impulsionará para a linguagem expressiva. Devido à ação de brincar a criança evidencia uma série de habilidades antes de falar, sendo o ato de brincar é uma fonte de desenvolvimento.

Em contribuição ao referido Bordignon (2008 apud Erikson, 1998, p. 47), propõe que o desenvolvimento da dimensão lúdica das crianças acontece nas seguintes formas:

a) na auto esfera das sensações do próprio corpo, isto é, a criança percebe-se em seu corpo, pensa e se expressa em cada uma de suas partes e membros;

b) na microesfera para os brinquedos, isto é, os brinquedos são, de certa forma, uma extensão de si mesma, de sua maneira de pensar, sentir e viver a vida; por eles manifesta seus sonhos, desejos, anseios, bem como as limitações de afetos e relações; e

c) na macro esfera que se refere aos outros, em termos dos conteúdos de relacionamentos que mantém com os outros, na figura dos adultos e dos seus pares. De grande valia é observar como a criança 
desenvolve cada uma destas dimensões na sua atividade lúdica e dramática.

O Professor tem que ter fundamentos teóricos sobre a capacidade de desenvolvimento das crianças que consiste na somatória dos dois níveis real e potencial, que o induz ao amadurecimento. Negrine (2002) defende a tese de Vygotsky, que o indivíduo amadurece (processo biológico) porque é capaz de aprender, e não o contrário: o indivíduo aprende porque amadurece como afirmam a maioria dos psicólogos contemporâneos.

\subsection{Compreender como se forma o conhecimento relativo às emoções}

O conhecimento humano pode ser algo adquirido, com o passar do tempo, em diversos meios onde ele vive. Os primeiros momentos de aprender acontece na família enquanto criança. Neste ambiente, as primeiras impressões associadas aos costumes e hábitos são passados de geração a geração no intuito de formar a concepção de pessoa E estas concepções dão subsídios às grandes mudanças de comportamento necessárias à vida toda. Os primeiros conhecimentos familiares são rudimentares, mas vão se aperfeiçoando na medida em que as práticas cotidianas se materializam.

Segundo Freitas (2011, p. 27), “O sentido que damos à vida e a forma como nos relacionamos estão ligados diretamente à cultura em que vivemos, servindo como uma espécie de lente através da qual olhamos o mundo à nossa volta”.

Ao longo da vida o sujeito passa a frequentar outros ambientes além do ambiente familiar, os quais lhe dão base para a convivência social. Neste momento surgem os confrontos de novas ideias e a partir das vivências de outros indivíduos somam outros costumes, outros hábitos e novas formas de pensar e agir. Freitas (2011, p, 27), ainda afirma que os sentimentos de amor, de afeto, de beleza e, por que não dizer, de estranhamento, de distanciamento e de aproximação estão permeados pela cultura de onde vivemos ou que nos foi passada pelos nossos ancestrais.

A convivência em determinados grupos sociais vai propiciar ao sujeito, diversas formas de abordagens para compreender os diferentes tipos de costumes presente nos mais diversos grupos sociais que existem. E a partir daí vão surgindo formas de organização social decorrente das regras estabelecidas no sentido de transformar as situações do dia a dia em práticas harmoniosas onde os elementos constituintes do grupo possam viver e gozar dos mesmos direitos.

Na opinião de Michaliszyn (2008, p. 29), para que o viver e o conviver em sociedade tornem-se possíveis, os grupos sociais estabelecem para si um conjunto de regras, os quais são aceitos coletivamente.

As experiências vividas são resultado das reflexões acerca de contextos da realidade. Estes contextos são analisados na mente humana para que possam ser tratados de forma verdadeira e uma vez havendo a constatação da verdade, tal conhecimento adquirido é passado de uma para o outro.

Os elementos constituintes das tomadas de decisão de cada indivíduo são formados a partir das sensações em relação ao mundo em que vive. As sensações são frutos das percepções dos fenômenos naturais ou convicções que criamos por meio de observação à outro indivíduo. As expressões pessoais são criadas intrisecamente ou extrincecamente. 
Michaliszyn (2008, p. 20), contribui dizendo que "pensamentos, ações, emoções, não são, portanto, formas inatas ou herdadas biologicamente, mas resultam de experiências e relações impostas pelo outro no decorrer de nossa inserção na vida social [...]".

Cada indivíduo é capaz de formar uma opinião a respeito do outro a partir da observação das ações por ele produzidas. Desta forma, podemos concluir que as emoções são construídas sob influência pessoal e social, seja no individualismo ou na coletividade.

\subsection{Obter Conhecimento sobre Emoções, Segundo Análise Teórica}

A construção do conhecimento sobre as emoções acontece na medida em que as ações são expostas em algum momento da vida humana. As tomadas de decisões constituem em práticas que revelam a personalidade de cada indivíduo. Tais práticas, se não forem administradas com cuidado pode levar o indivíduo a tomar decisões erradas na hora errada causando um tremendo desconforto para a vida futura. "Ao formar-se como pessoa, o ser humano também se descobre indivíduo, ímpar, único, solitários". (MICHALISZYN, 2008, p. 58).

Controlar as emoções é uma arte que depende de muita flexibilidade e conhecimento sobre si. Cada corpo é regido por emoções fortes que podem sobrepor sobre a vontade humana na medida em que as situações dramáticas do cotidiano venham ocorrer. Atitudes tomadas sem um conhecimento prévio contribuem com a formação dos distúrbios mentais onde o sujeito passa a não controlar seus instintos e cometem ações indesejadas constatadas como crime no contexto de organização social o qual vivemos.

Michaliszyn (2008, p. 49), faz uma reflexão importante sobre as diferenças da pessoa humana.

Quando pensamos a questão das diferenças individuais, privilegiadamente Foucault e seus escritos sobre disciplinamento de corpos e mentes e sobre a estigmatização de "loucos" e "criminosos" produzidos por este mesmo tipo de pensamento. Modelos ideais de homem, de mulher, de cidadão e de trabalhador são difundidos e legitimados, sustentando uma noção de igualdade, que busca a aniquilação da diferença e mesmo do diferente, ao mesmo tempo em que produzem a essencialização da diferença que cria a impossibilidade da igualdade. (MICHALISZYN, 2008, p. 49).

O desenvolvimento da personalidade de cada ser humano contribui com as tomadas de decisões de cada um. À medida que o ser humano agrega valor cultural e emocional sobre si, ele sente segurança no que diz e faz. O controle emocional depende de como tal pessoa compreende o mundo a sua volta. A concepção do certo ou errado é construída no coletivo para atender as regras de segurança estabelecidas em prol da boa convivência entre os elementos de um determinado grupo social.

De acordo com Michaliszyn (2008, p. 59),

O controle dos sistemas que regulam as relações sociais é garantido pela definição dos papéis sociais de cada indivíduo e pela internalização da realidade, através do processo de socialização, que acompanhará os indivíduos desde o seu nascimento até a morte. (MICHALISZYN, 2008, p. 59).

As mudanças que o ser humano provoca, em qualquer contexto que seja, normalmente é por vontade própria dependente da forma em que ele se comporta. O comportamento é o resultado do estado em que 
se encontra a mente. O equilíbrio emocional pode ser considerado como um estado de bem-estar.

A mudança de estado mental acontece sem qualquer ordem consciente não sendo possível estabelecer tempo e hora para testar qualquer procedimento estranho. Basta vermos algo que não nos agrade que o sentimento de poder ou de baixa estima se apresenta como controle mental, tornando-nos reféns do sentimento. Neste caso, a mente humana se organiza para que os estímulos emocionais entrem em harmonia com o corpo para que juntos possam resolver o conflito existente.

Antunes (2012, p. 17), afirma que:

Para Freud, a maneira como somos e pensamos e a maneira como nos comportamos e construímos nossa baixa - estima é produto da relação entre nosso consciente e nosso inconsciente, e assim somos como que dirigidos por determinações que fogem ao império de nossa vontade ou intenção. (ANTUNES, 2012, p. 17).

No entanto, o controle emocional é considerado como a forma mais simples de resolver os conflitos porque possibilita a criação de novas estratégias mentais, calculadas sem risco de desastre, no sentido de contribuir com a sintonização do pensamento organizado que leva a compreensão dos fatos.

\subsection{Perceber a Importância da Educação Emocional}

O desenvolvimento social da civilização humana vem ocorrendo desde o surgimento dos primeiros grupos humanos na Terra, mas nem sempre houve harmonia entre os elementos dos grupos. Com o passar do tempo houve a necessidade de se organizar a vida social para que todos pudessem viver em harmonia. Assim, surgem as normas organizacionais, estabelecidas com o objetivo de desenvolver e mente de forma que os elementos pudessem aceitar uns aos outros com suas diferenças.

A medida que os elementos humanos foram se adaptando às normas de convivência a construção do conhecimento e do que é ser humano, também se materializava. Para Freitas, (2011, p. 29), transmitimos aos semelhantes à noção do que é ser humano através de um processo de socialização, sendo que nenhum outro animal pode fazer isso por nós.

As diversas formas de organização social existem porque a mente humana se desenvolveu ao longo do tempo, e com muita criatividade foi percebido que havia formas cabíveis de tomar decisões perante ás situações problemas existentes no intuito de viver em harmonia.

A este respeito considera-se que psicologicamente o ser humano atribuiu valor a sua forma de pensar e ver o mundo a sua volta, sensibilizando-se uns com os outros e levando em consideração o valor pessoal de cada ser, colocando-se um no lugar do outro para juntos conseguirem compreender o comportamento mental de cada indivíduo e tentar restabelecer a ordem quando esta sai fora do controle.

Parolin, (2007, p. 5), contribui dizendo que:

As emoções do ser humano são as manifestações da afetividade e a expressão dos sentimentos. Têm caráter de visibilidade e é por meio delas que os educadores podem conseguir pistas do que está acontecendo com seus alunos: respiração, agitação, expressões faciais, olhares etc. Sua grande função é 
mobilizar o outro e garantir atenção e cuidados. (PAROLIN, 2007, p..5)

A postura do indivíduo de cada grupo social se encarrega de transparecer todo o seu sentimento, seja superficial ou real. A conduta do bem-estar social privilegia a mente sã porque considera um ser organizado intelectualmente. A organização da mente humana se dá no momento em que o extremo chega próximo do caos.

Um exemplo de ambiente social onde os conflitos emocionais acontecem é na instituição escolar. Na escola acontecem as primeiras manifestações de incertezas entre os alunos que por sua vez adquirem conhecimentos diversos para compreender a sua própria existência. Nela também surgem ideias que devem ser respeitadas e trabalhadas pelos professores no sentido de garantir o controle de situações adversas fazendo com que os alunos tenham segurança de seus próprios atos e conheçam a responsabilidade de cada um diante de qualquer situação que possa surgir.

Segundo Jacó (2012, p. 61),

Educação é transformação e desenvolvimento do homem, faz-se necessário completá-la afirmando que o processo educacional deve ser entendido, também e essencialmente, como aquele que permite ao homem, com toda a sua historicidade e singularidade, se apropriar do conhecimento produzido historicamente pela humanidade. (JACÓ, 2012, p. 61)

Neste sentido, podemos concluir que educar a mente humana é colocar em prática atividades cerebrais construtivas do saber para que o corpo possa reagir com qualidade emocional que priorize a vida.

\subsection{Compreender as Estratégias Utilizadas para o Desenvolvimento das Emoções}

As estratégias pedagógicas que possibilitem o desenvolvimento das emoções encontram-se num repertório de atividades pedagógicas que podem ser aplicadas nas escolas com as crianças, desde seus primeiros anos de vida.

As práticas pedagógicas têm como objetivos dar sentido a vida dos educandos, de forma que eles percebam a importância de conviver saudavelmente e que isto favoreça o relacionamento interpessoal.

Antunes (2011, p. 36), afirma que Piaget descreve quatro fatores importantes que devem ser levados em consideração, pelo professor, no planejamento de atividades para as crianças na escola.

$1^{\circ} \mathrm{O}$ progresso de amadurecimento vai tornando-o superador de desejos antes impossíveis. Como ficar de pé, por exemplo. Mas somente ficará quando os músculos de sua perna "amadurecerem" o suficiente para sustentá-lo.

$2^{\circ} \mathrm{Na}$ aprendizagem através da experiência o corpo recebe informações sensório-motoras e, com graus de sofisticação diferentes, irá associando essas informações a ações e raciocínios.

$3^{\circ} \mathrm{A}$ interação social que acontece ao brincar, viver em meio à outros absorverá exemplos, aprenderá loções, sobretudo quando, no final desse ciclo, conquistar o império extraordinário da fala e, através da mesma, novos e múltiplos raciocínios. 
$4^{\circ} \mathrm{O}$ equilíbrio é um fantástico processo de reunir o amadurecimento, a experiência e a interação social para construir estruturas e sistemas para olhar o mundo.

As atividades em que as crianças desenvolvem com alegria são merecedoras de destaque. Brincando as crianças fazem as atividades escolares com prazer e constrói o conhecimento sistematizado. A escola que proporciona momentos de descontração nas aulas oferece oportunidade para que o desenvolvimento integral da criança aconteça de forma adequada, fazendo com o trabalho do professor seja repleto de alegria e satisfação também.

"A escola é construída como um espaço que comporta uma complexa trama de relações sociais ente os sujeitos envolvidos, que incluem alianças e conflitos, imposição de normas e estratégias individuais ou coletivas, de transgressão e de acordos”. (MICHALISZYN, 2011, p. 78-79).

A partir do momento em que as relações vão acontecendo o sentimento de pertencimento de grupo fortalece contribuindo com o amadurecimento emocional das crianças. O que elas aprendem na escola também leva para casa.

Segundo Michaliszyn (2011, p. 83),

A escola é um espaço aberto, transcendente de criação, e, enquanto tal, a beleza daquilo que nela se passa "vem do fato de que não é um registro da realidade, mas lugar privilegiado de trânsito entre o real e seus múltiplos sentidos, entre a tradição e a criação".

Desta forma, há que se considerar que o desenvolvimento emocional depende de como o sujeito vê as coisas ao seu redor e isto coloca a escola numa postura de transformação social da mente, uma vez que nela acontece o encontro de costumes e hábitos diferenciados, que juntos, tendem a transformar em aprendizado.

$\mathrm{Na}$ escola trabalham-se as questões de ética para que os alunos possam construir valores morais. Das atividades mais simples até as mais complexas, conforme o amadurecimento de cada um.

Freitas (2011, p. 47) afirma que "um exercício saudável na busca pela compreensão do outro é nos questionarmos sobre coisas que julgamos corriqueiras em nossas vidas, como por exemplo: E se não fosse assim? Por que sempre dizem que isso é natural?" Portanto, existem muitas formas de provocar a mente humana para compreender como o outro reage e como o outro vê o mundo e direciona seu pensamento na condição de receptor de mensagens ou de mero comunicador.

As relações sociais fazem com que o sujeito possa gostar de pertencer a um determinado grupo e sentir-se parte dele. Isto é uma conquista diária que acontece na escola e o aluno acaba construindo sua identidade neste processo. "A identidade se constrói dentro do próprio grupo e se faz a partir de uma relação de alteridade. Ou seja, necessita do "outro" para poder se definir". (FREITAS, 2011 p. 50).

\section{CONSIDERAÇÕES FINAIS}

Em se tratando da formação da criança, entender o que é emoções diante das significações atribuídas em sua educação e a relação às emoções que se constituem em cada nível de seu desenvolvimento, é 
necessário que se compreenda o processo das emoções para aprendizagem pela mesma.

Desta forma o artigo, com base na área da educação, tendo uma forma de refletir e compreender a criança como ser humano especial, propõe um olhar mais atento ao conhecimento das emoções na educação, tem como meta proporcionar a criança momentos prazerosos de aprendizagem, do diálogo, chamado a atenção para o conhecimento de si dentro de acordo a cada faixa etária adequada e limitações por ela experimentadas.

E para que os professores estejam cientes de seu papel formador das pequenas mentes, proporciona um diálogo da prática cotidiana e da interação da criança com o meio através do equilíbrio das emoções com a dimensão física (corpo), afim de contribuir para as concretizações importantes para o desenvolvimento do aluno.

De acordo as contribuições encontradas deste artigo tratando do significado das emoções na educação das crianças conta com fundamentos argumentando a contribui que a ludicidade tem na educação infantil, sendo que foi de extrema importância entende-se assim que a proposta pedagógica contribuiu com o desenvolvimento deste assunto.

Primeiramente uma análise do que seria os conceitos, as considerações relevantes para a compreensão do objeto de estudo.

Com a contribuição de autores este artigo contribui para um maior entendimento da importância da educação emocional, no sentido de desenvolver e melhorar a aprendizagem através do lúdico.

\section{REFERÊNCIAS}

ANTUNES, Celso. O jogo e a educação infantil: falar e dizer, o olhar e ver, escutar e ouvir. 8. Ed. Petrópolis, RJ: Vozes, 2012.

ARANTE Valeria Amorim, Afetividade na escola: (Alternativas teóricas e práticas), São Paulo: Summus, 2003.

BOCK, Ana Mercês Bahia.Psicologia. São Paulo: Saraiva, 1999.

BORDIGnON, Nelson Antonio. A Formação dos Professores na Perspectiva da Psicanálise Cultural. Brasília: Universa, 2008.

Elementos de Antropologia, 2016.

BRUNER, J. “As funções do ensino". In: Morse, W. e Wingo, G. M. Leituras em Psicologia Educacional da criança. São Paulo, Nacional, 1979.

DAMÁSIO António R. Em busca de Espinosa. São Paulo: Companhia das Letras, 2004.

O Erro de Descartes: Emoção, Razão e o Cérebro Humano, São Paulo: Companhia das

Letras, 1996. 
2000.

ERIKISON, Erik. Identidade, Juventude e crise. $2^{\circ}$ ed. Rio de Janeiro: Guanabara, 1987.

FREITAS, Fátima e Silva. A diversidade cultural como prática na educação - Curitiba: Ibpex, 2011.

FREUD, S. Três ensaios sobre a sexualidade. Rio de Janeiro: Imago, 1973.

FERREIRA, A.B.H., Dicionário da Língua Portuguesa, Rio de Janeiro: Nova Fronteira, 1986.

GOLEMAN, Daniel. Inteligência emocional: a teoria revolucionária que redefine o que é ser inteligente. Rio de Janeiro: Objetiva, 2007.

Inteligência emocional. 4. ed. Rio de Janeiro: Objetiva, 1996.

IMODA, Franco. Psicologia e mistério, o desenvolvimento humano. São Paulo: Paulinas, 1996.

JACÓ-VILELA, AM., and SATO, L., orgs. Diálogos em psicologia social [online]. Rio de Janeiro: Centro Edelstein de Pesquisas Sociais, 2012. 482 p. ISBN: 978-85-7982-060-1. Available from SciELO Books <http://books.scielo.org>.

JOSÉ FILHO, M. Pesquisa: contornos no processo educativo. In: JOSÉ FILHO,

MATURANA, Humberto.Emoções e linguagem na educação e na política. Belo Horizonte: Ed. UFMG, 1999b.

MICHALISZYN, Mario Sérgio. Educação e diversidade - Curitiba: Ibpex, 2008.

NEGRINE, Airton. O corpo na educação infantil. Caxias do Sul: 2002.

OLIVEIRA, Zilma Morais Ramos. Educação infantil muito olhares, 9 ed. São Paulo: Cortez, 2010.

PAROLIN, Izabel. As emoções como mediadoras da aprendizagem - Artigo publicado nos anais do VII Encontro de Educação Da PUCPR - EDUCERE Saberes Docentes em Novembro de 2007.

PIAGET, Jean. Seis estudos de psicologia. Rio de Janeiro, 2004.

PILETTE, Nelson. Psicologia educacional, São Paulo, Ática, 1985.

SCHUMACKER, Fabiane, (coord.) Et all. As múltiplas relações nos diversos ambiente da escola. Porto Alegre, 2005

TIBA, Içame. Ensinar aprendendo. São Paulo, Gente, 1998.

VYGOTSKY, L. S. A formação social da mente. São Paulo: 1989. 
WALLON, Henri. Psicologia e Educação da criança. Lisboa: Veja, 1996

A evolução psicológica da criança. Lisboa, Portugal, 1995.

[1] Pós-graduação em Psicopedagogia e Ludopedagogia Clínica e Institucional 620h. Graduação em Pedagogia Licenciatura plena).

${ }^{\text {[2] }}$ Ortopatia o correto desenvolvimento da área afetiva. Dada a unidade fundamental da vida humana, esta correção envolve a verdade do objeto e a sua objetividade, mas envolve também o grau de liberdade com que o objeto vem desejado, querido, amado. $\mathrm{O}$ 'pathos' é então considerado como área afetiva que, no ser humano, constitui um irrenunciável ligame entre o 'bios', entendido como vital, o corpóreo e o 'logos', a componente cognitiva e racional. Imoda (1996, p. 614) apud Bordignon (2008, p. 24)

${ }^{[3]}$ Ortodoxia em sentido mais estreito, é a interpretação correta e o respeito de uma verdade, como crença ou dogma. Em sentido mais largo, é o correto funcionamento do conhecer humano, como função de objetividade e de transcendência. Imoda (1996, p. 614) apud Bordignon (2008, p. 24)

${ }^{\text {[4] }}$ Ortopraxis entendida como respeito pelo agir corretamente, a partir da verdade. Insiste nas diversos formas de disciplinação da vontade. Imoda (1996, p. 266 e 540) apud Bordignon (2008, p. 24).

\section{PUBLIQUE SEU ARTIGO CIENTÍFICO EM:}

https://www.nucleodoconhecimento.com.br/enviar-artigo-cientifico-para-submissao 